\title{
KOCHER'S METHOD IS 3,000 YEARS OLD
}

\author{
M. Kamel Hussein, Cairo, Egypt \\ Formerly Professor of Orthopaedics, University of Cairo
}

There was nothing unusual in the decision of Rameses II, 1200 B.C., to build a tomb for himself at Thebes on the western side of the Nile, at a place now known as Deir el Medineh, near Luxor. As usual he commissioned a sculptor, Ipuy by name, to paint the walls of the

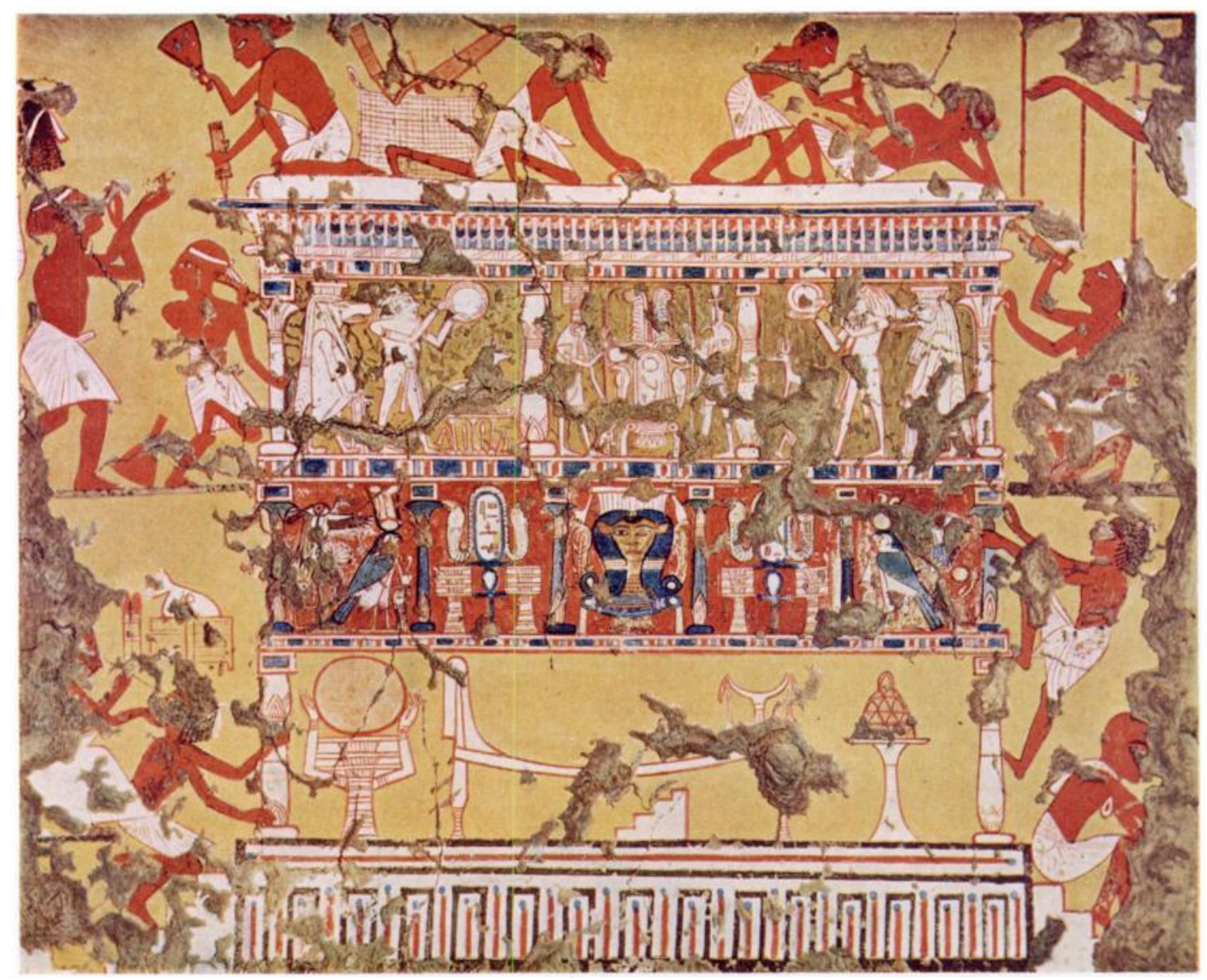

FIG. 1

Wall painting. Tomb of Ipuy, 1200 B.C. From Davies: Two Ramesside Tombs at Thebes, Plate XXXVIII. (Reproduced by kind permission of The Metropolitan Museum of Art, New York.)

tomb. It was Ipuy who was original. He seems to have had little respect for the traditional scenes painted by his predecessors over the centuries. Realistic scenes of fishing and hunting, in spite of their precision and skilful execution, did not impress him much; nor was he moved by the classic paintings on the walls of tombs all over the country from Memphis to Thebes, in which endless processions of offerings to the gods were depicted. He must have been bored by the classic scenes of religious dancing, of bulls slaughtered as sacrifices, of corn being ground and baked to make sacred bread which was to be offered in quantities to the dead, and of boats carrying souls to heaven for judgement by the gods. 
When Ipuy came to build a tomb for himself he preferred to paint more worldly scenes, showing events occurring around him during the building of the tomb. His paintings are fresh, often amusing, and sometimes enlightening (Fig. 1).

In one scene (Fig. 2) a labourer is shown screaming and gesticulating in a very lively manner. The blade of an axe, detached from its handle, has fallen on his foot and caused him severe pain.

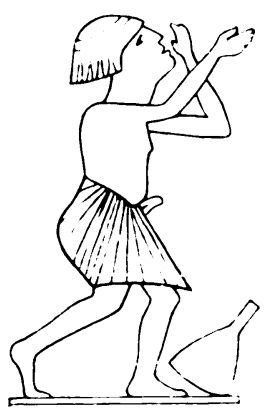

Fig. 2

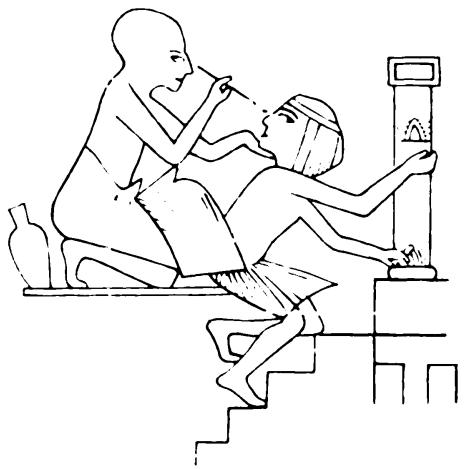

Fig. 3

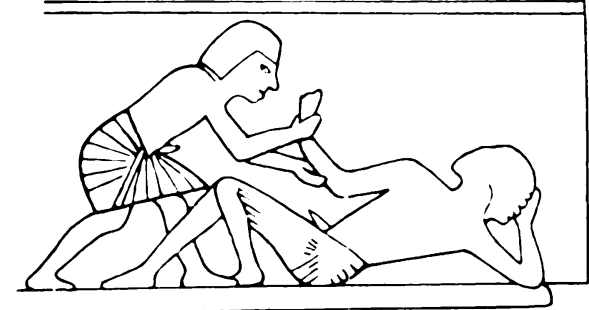

FIG. 4

Details of Figure 1.

Another scene (Fig. 3), more difficult of interpretation, shows a labourer turning round presenting his eyes to another man who is holding a short rod. It is possible that this is the drawing of a labourer who had a splinter in his eye and a physician preparing to extract it.

The most interesting picture in this remarkable wall painting is, however, the one shown in Figure 4. A man, presumably a patient, lies on the ground while another man (a physician?) holds his arm, flexed at the elbow, with both hands, one holding the elbow and the other grasping the wrist. The manoeuvre is so typical that there seems little doubt that we are

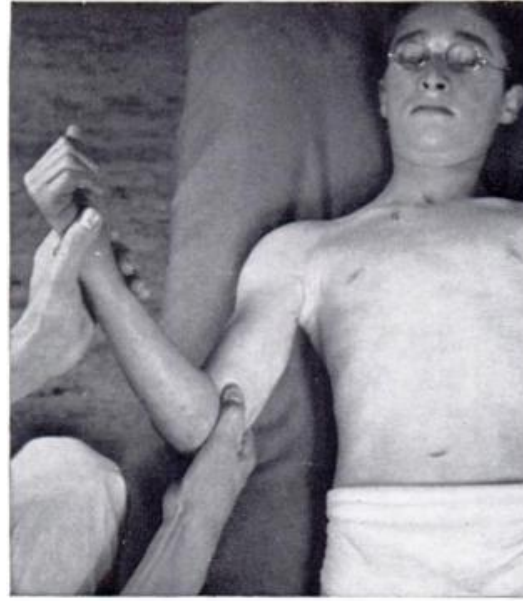

Fig. 5

Kocher's method of reducing a dislocated shoulder. Reproduced from WatsonJones: Fractures and Joint Injuries. E. \& S. Livingstone Ltd., by kind permission. here witnessing the reduction of a dislocated shoulder by lateral rotation. In fact, if we compare this picture with that illustrating Kocher's method in WatsonJones's textbook (Fig. 5) we find a close resemblance between the two.

The extraordinary thing is that this physician does not work directly on the displaced humeral head as recommended by all authorities, including Hippocrates, up to the nineteenth century. It seems incredible that an ancient practitioner should be aware of this fine technique which was missed for so long by the most learned, and which could hardly be discovered accidentally or by mere theoretical consideration. The fact is that some people are naturally endowed with the knack of setting fractures and reducing dislocations. A labourer at a sugar factory near Cairo told me once that he felt he could do this successfully. He wanted to see how these things were done by qualified practitioners so that he might do them properly. I told him not to try, for he would lose his intuition without gaining sufficient knowledge to replace it.

In his masterly treatise on dislocation of the shoulder, Hippocrates makes no reference to reduction by lateral rotation. Only once, while discussing one of the methods of reduction which he did not recommend for it was not " natural," does he mention, in a very vague way, 
that the head rotates itself in place. The methods of reduction recommended by Hippocrates depend essentially on direct approach to the humeral head by hand or by a padded wooden bar, or the heel of the physician reinforced by a padded ball. Any of these is introduced between the head and the chest wall. The head is thus bodily moved away from the chest wall. This is helped by adduction of the arm or by traction and counter-traction. Figure 6 gives a representation of one of these manipulations as recommended by Hippocrates and practised up to the end of the last century.

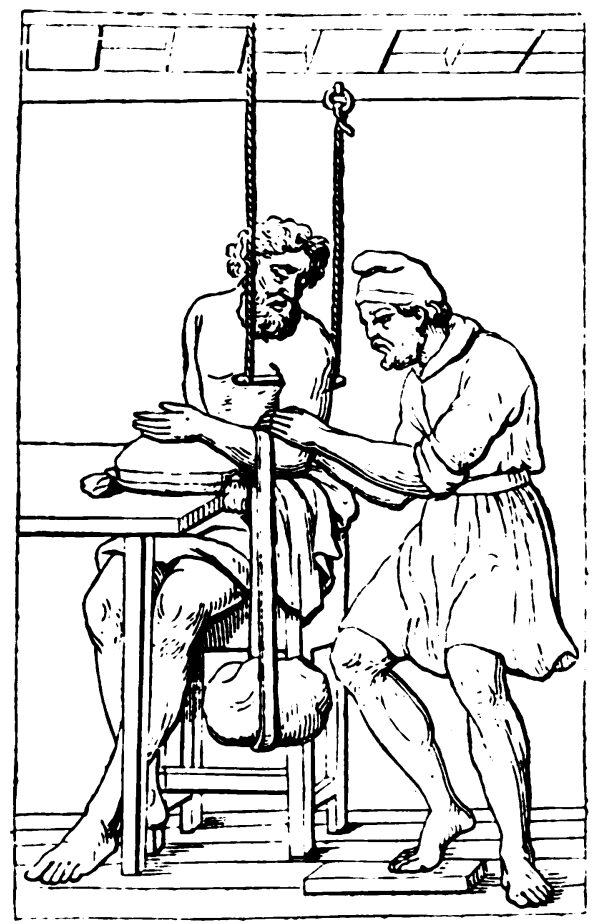

Fig. 6

Method of reduction of dislocated shoulder after Hippocrates.

The idea of lateral rotation as the principal factor in reducing dislocated shoulders is a stroke of genius. It occurred to the Ancient Egyptian surgeons 3,000 years before it was rediscovered by one of the greatest surgeons the world has ever seen. The method will, however, forever bear the name of Kocher.

I am indebted to Professor P. Ghalioungui, Professor of Medicine at Ain-Shams University, Cairo, for his help in the preparation of this article. He has written extensively and authoritatively on Ancient Egyptian medicine (see Ghalioungui 1963).

\section{REFERENCES}

Davies, N. de Garis (1927): Two Ramesside Tombs at Thebes. Robb de Peyster Tytus Memorial Series, Volume V. New York: The Metropolitan Museum of Art.

Ghalioungui, P. (1963): Magic and Medical Science in Ancient Egypt. London: Hodder and Stoughton. WATSON-JONES, Sir R. (1962): Fractures and Joint Injuries. Fourth edition, p. 480. Edinburgh and London: E. \& S. Livingstone Ltd. 